\title{
Lab-on-a-brane for spheroid formation
}

Citation for published version (APA):

Bianco, M., Zizzari, A., Priore, P., Moroni, L., Metrangolo, P., Frigione, M., Rella, R., Gaballo, A., \& Arima, H. (2019). Lab-on-a-brane for spheroid formation. Biofabrication, 11(2), 1-11. [021002]. https://doi.org/10.1088/1758-5090/ab0813

Document status and date:

Published: 01/04/2019

DOI:

10.1088/1758-5090/ab0813

Document Version:

Publisher's PDF, also known as Version of record

Document license:

Taverne

Please check the document version of this publication:

- A submitted manuscript is the version of the article upon submission and before peer-review. There can be important differences between the submitted version and the official published version of record.

People interested in the research are advised to contact the author for the final version of the publication, or visit the DOI to the publisher's website.

- The final author version and the galley proof are versions of the publication after peer review.

- The final published version features the final layout of the paper including the volume, issue and page numbers.

Link to publication

\footnotetext{
General rights rights.

- You may freely distribute the URL identifying the publication in the public portal. please follow below link for the End User Agreement:

www.umlib.nl/taverne-license

Take down policy

If you believe that this document breaches copyright please contact us at:

repository@maastrichtuniversity.nl

providing details and we will investigate your claim.
}

Copyright and moral rights for the publications made accessible in the public portal are retained by the authors and/or other copyright owners and it is a condition of accessing publications that users recognise and abide by the legal requirements associated with these

- Users may download and print one copy of any publication from the public portal for the purpose of private study or research.

- You may not further distribute the material or use it for any profit-making activity or commercial gain

If the publication is distributed under the terms of Article $25 \mathrm{fa}$ of the Dutch Copyright Act, indicated by the "Taverne" license above, 


\section{NOTE}

\section{Lab-on-a-brane for spheroid formation}

\section{Recent citations}

To cite this article: M Bianco et al 2019 Biofabrication 11021002

View the article online for updates and enhancements.

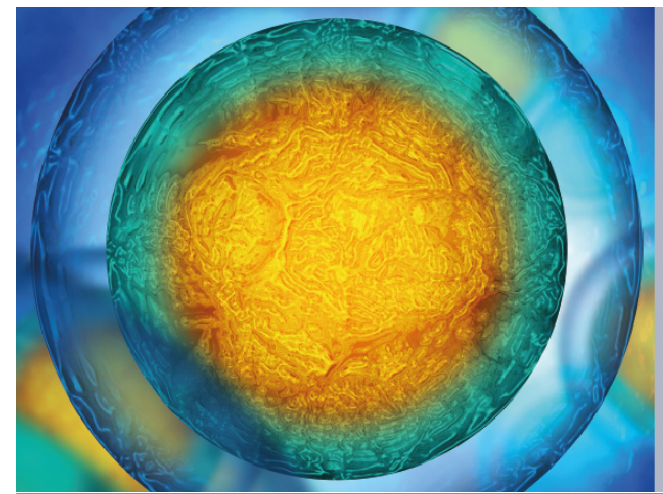

Biophysical Society $\quad$ IOP $\mid$ ebookS $^{\mathrm{TM}}$

$\overline{\bar{\equiv}}$

Your publishing choice in all areas of biophysics

research.

Start exploring the collection-download the first chapter of every title for free. 


\title{
Biofabrication
}

NOTE

\section{Lab-on-a-brane for spheroid formation}

RECEIVED
4 May 2018
REVISED
14 February 2019
ACCEPTED FOR PUBLICATION
18 February 2019
PUBLISHED
28 March 2019

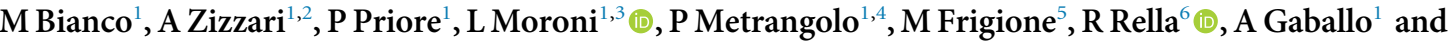 \\ V Arima ${ }^{1}$ (1) \\ 1 CNR-NANOTEC, Institute of Nanotechnology c/o Campus Ecotekne, Lecce, Italy \\ 2 Dipartimento Matematica e Fisica E De Giorgi, University of Salento, Lecce, Italy \\ 3 Maastricht University, MERLN Institute for Technology-Inspired Regenerative Medicine, department of complex tissue regeneration, \\ 6229ER, Maastricht, The Netherlands \\ 4 Laboratory of Supramolecular and Bio-Nanomaterials (SBNLab), Department of Chemistry, Materials and Chemical Engineering \\ 'Giulio Natta', Politecnico di Milano, Milan, Italy \\ 5 Department of Innovation Engineering, c/o Campus Ekotekne, University of Salento, via Monteroni, Lecce, Italy \\ 6 CNR IMM-Institute for Microelectronics and Microsystems, c/o Campus Ecotekne, via Monteroni, Lecce, Italy \\ E-mail: valentina.arima@nanotec.cnr.it
}

Keywords: spheroids, polydimethylsiloxane, lab-on-a-chip, lab-on-a-brane, millifluidics

\begin{abstract}
Lab-On-a-Brane (LOB) represents a class of Lab-On-a-Chip (LOC) integrating flexible, highly gas permeable and biocompatible thin membranes (TMs). Here we demonstrate the potentiality of LOBs as cell biochips promoting $3 \mathrm{D}$ cell growth. The human cancer cells MCF-7 were cultured into standard multiwells (MWs) and into polydimethylsiloxane (PDMS) MWs, LOCs, and LOBs of different wettability. Surface treatments based on oxygen plasma and coating deposition have been performed to produce hydrophilic, hydrophobic, and oleophobic chips. By a comparison between all these chips, we observed that $3 \mathrm{D}$ cell aggregation is favored in LOBs, independent of substrate wettability. This may be attributed to the TM flexibility and the high oxygen/carbon dioxide permeability. Ultimately, LOBs seem to combine the advantages of LOCs as multi-well microfluidic chips to reduce operation time for cell seeding and medium refresh, with the mechanical/morphological properties of PDMS TMs. This is convenient in the perspective of applying mechanical stimuli and monitoring cell stiffness, or studying the metabolism of molecules permeable to PDMS membrane in response to external stimuli with interesting outcomes in cellular biology.
\end{abstract}

\section{Introduction}

Membrane-based microfluidics represent a new frontier of Lab-On-a-Chip (LOC) technology [1-3]. To remark the peculiar properties of LOCs integrating thin membranes (TMs), a novel acronym has been created to describe the 'Laboratory on a Membrane', or shortly LabOn-a-Brane (LOB) [4]. The material of choice for LOBs is polydimethylsiloxane (PDMS), due to its elasticity, easy microstructuring by soft lithography, biocompatibility, gas/small molecule permeability and wide range of chemical functionalization. Furthermore, thanks to the optical transparency, PDMS LOBs allow easy and real time monitoring of the sample through microscopy.

PDMS TMs of controlled stiffness, porosity, and wettability can be produced and integrated into LOBs to be used as valves [5-7], gas sensors [8-10] or biosensors [11, 12].
In the field of two dimensional (2D) cell biochips, PDMS TMs have been used to monitor cell morphology in response to external stimuli [13], or as a tool to study cancer cell invasiveness [14], metabolite generation [15] or to deliver reagents for immunostaining [16]. On the other hand, the influence of substrate stiffness on cell activity is subject to a great deal of research and represents the topic of mechanotransduction [17].

Beyond 2D cell cultures, the growth of 3D multicellular spheroids, that better mimic the in vivo tissue features, have been demonstrated to be advantageous in PDMS chips compared to standard spheroids cultured in commercial multiwells (MW) in terms of reduced operation time for cell seeding and medium refresh [18] and for potential integration with a number of functions, such as cell sorting, drug screening, and molecular assays [16]. Furthermore, 3D cell 
cultures represent a fundamental step towards the development of 'organs-on-chips', microfluidic platforms able to mimic continuous perfusion and physiological cell-matrix and cell-cell interactions with organ-level complexity that have been proposed to fill the gap between in vitro and in vivo systems for preclinical research [19-23].

The specific microwells for multicellular spheroid growth have to satisfy precise pre-requisites concerning: (1) chamber shape and volume, (2) low-attachment surface (3) cell to surface ratio, (4) gas permeability to enable $\mathrm{O}_{2}$ and $\mathrm{CO}_{2}$ exchange [24-30].

Here, a LOB made up of milliwells and millifluidic channels in PDMS is proposed and the parameters driving the 3D assembly of the cells on the membrane investigated. In particular, the influence of geometric constraints (as milliwell volume and cell density), the stiffness and the wettability of the wells have been taken into consideration. Although the shape of the wells is known to influence $3 \mathrm{D}$ aggregation, the production of concave or conical shape wells was not considered in this study given to their higher fabrication costs $[25,30]$. Furthermore, the basement of LOB wells is expected to assume a curved shape after liquid loading because of the membrane flexibility [10,31].

MCF-7 cells, a breast cancer line, are used here to demonstrate the formation of mammospheres and validate the LOB. Several reports have shown that moderately hydrophilic surfaces (i.e. contact angle of $40^{\circ}-50^{\circ}$ ) promote cell attachment more than hydrophobic or very hydrophilic surfaces [32]. Due to its hydrophobicity, PDMS has been used without any surface treatment as substrate for spheroid growth [16], even with the drawback that a high hydrophobicity and porosity may allow an unspecific absorption/adsorption of small molecules [33] and alter the cell culture conditions. To reduce this undesired effect, some coatings with fluoro-compounds can be used because of their strongly biofouling properties [34-36]. To assemble fluorinated coatings on PDMS, we recently exploited a strategy based on Fluorolink ${ }^{\circledR}$ F10 (referred in the text as F10) in the presence of a protein, the hydrophobin HFBII, which acts as a primer and creates a biocompatible, grafted oleophobic coating [37, 38]. Compared to other deposition methods of fluorinated coatings on polymers, the HFBII/F10 self-assembly proceeds rapidly and spontaneously from aqueous solution and does not involve energy-intensive procedures [39]. This makes it sustainable from the economic and environmental viewpoints, particularly in the case of fabrication of singleuse disposable chips.

\section{Experimental section}

MW plates for cell culture containing 24 wells with a culture area of $1.9 \mathrm{~cm}^{2}$ were purchased from Thermo
Scientific (Denmark). Sylgard-184, a two-part poly (dimethylsiloxane) (PDMS) elastomer, was purchased from Dow Corning (USA).

For the TM fabrication, CLEVIOS PH 500 and toluene were purchased from Heraeus Clevios $\mathrm{GmbH}$ (Germany) and J T Baker (USA) respectively. Dulbecco's Modified Eagle Medium high glucose (DMEM), fetal bovine serum (FBS), penicillin and streptomycin were purchased from Sigma Aldrich (Milan, Italy). The protein HFBII was produced using recombinant strains of T reesei, purified by RP-HPLC, as described previously and lyophilized before use [40-42]. F10 was obtained from Solvay Specialty Polymers (Italy). Milli$\mathrm{Q}$ water with a resistivity of $18.2 \mathrm{M} \Omega \mathrm{cm}$ was used.

\subsection{Chip fabrication}

The MW-PDMS chips are commercial MWs (18 mm of diameter and $3.8 \mathrm{ml}$ internal volume), in which a volume of $400 \mu \mathrm{l}$ of PDMS pre-polymer mixed with its curing agent at a ratio of 10:1 was poured. Such a volume was opportunely chosen in order to obtain a layer of PDMS with a thickness of about $1 \mathrm{~mm}$. The polymerization was carried out at room temperature for $24 \mathrm{~h}$.

The LOC and LOB chips have been fabricated using a conventional soft lithography process. The platforms were obtained by casting PDMS pre-polymer and curing agent onto a plastic mold fabricated via stereolithography [9]. The mold presents the design of the fluidic channels ( $1 \mathrm{~mm}$ wide, $2 \mathrm{~mm}$ deep, and $5 \mathrm{~mm}$ long) and of the chambers for cell seeding (diameter of $5 \mathrm{~mm}, 100 \mu \mathrm{l}$ internal volume). The polymerization was performed overnight in an oven at $60^{\circ} \mathrm{C}$, then the PDMS replica was accurately separated from the mold. Then, smaller wells for cell growth (internal volume of about $4 \mu \mathrm{l}$ ) have been obtained by punching a circular area with a diameter of $1.5 \mathrm{~mm}$ on the bottom of the chambers for cell seeding. The punched wells have been bonded via an oxygen plasma treatment to a $1 \mathrm{~mm}$ thick PDMS slide for LOC fabrication, and to a thin PDMS membrane ( $2 \mu \mathrm{m}$ thick) for LOB fabrication. Membranes have been prepared by spin coating a solution of PDMS pre-polymer and curing agent diluted in toluene. The solution was deposited and polymerized at $60{ }^{\circ} \mathrm{C}$ overnight onto clean glass substrates covered by a water soluble sacrificial layer of CLEVIOS PH 500. The chip mold and the PDMS TMs were both plasma oxidized and put in conformal contact. Afterwards the chip-membrane assembly was put into water while stirring, to transfer the TM to the LOB and remove the glass substrate. Then, washing by pure water was performed to remove CLEVIOS PH 500 residues on the membrane side that was in contact with the glass substrate. 


\subsection{Chip functionalization}

All the MWs, LOCs and LOBs have been plasma oxidized. LOCpl and LOBpl have been used soon after plasma treatment, while LOC-PDMS and LOB-PDMS after $3 \mathrm{~d}$ to partially restore their hydrophobicity. After oxygen plasma treatment, MW-F10, LOC-F10 and LOB-F10 have been obtained by functionalizing the chips with HFBII and F10 at a controlled $\mathrm{pH}$ of 4, through the use of $10 \mathrm{mM}$ acetate buffer solution [37]. Initially few microliters of $0.1 \mathrm{mg} \mathrm{ml}^{-1} \mathrm{HFBII}$ solution have been poured in MW-F10, LOC-F10 and LOBF10 respectively. After an incubation of $30 \mathrm{~min}$, the HFBII solution has been withdrawn from each chamber. Then, three washings with clean buffer solution were practiced. As following step, the same procedure was repeated using a $1 \mathrm{mg} \mathrm{ml}^{-1}$ solution of F10 and clean buffer for the three next washing. At the end, the chambers were rinsed with Milli-Q water and accurately dried with nitrogen.

\subsection{Chip sterilization}

The chips have been washed with $\mathrm{EtOH} 70 \%$ and sterilized PBS. Then they have been treated with UV for $2 \mathrm{~h}$ from both front and back sides. Afterwards, an aliquot of $100 \mu \mathrm{l}$ of a suspension with human cancer cell line MCF-7 $\left(50 \times 10^{3}, 5 \times 10^{3}\right.$ or $5 \times 10^{2}$ cells ml $\left.^{-1}\right)$ in high glucose DMEM supplemented with $10 \%$ FBS, $100 \mathrm{U} \mathrm{ml}^{-1}$ penicillin and $100 \mu \mathrm{g} \mathrm{ml}^{-1}$ streptomycin was seeded in the chips. Cells seeded have been allowed to grow for $2-5 \mathrm{~d}$ at $37^{\circ} \mathrm{C}$ in an atmosphere of $5 \% \mathrm{CO}_{2}$. Optical images of spheroids in the chips have been acquired using a Nikon microscope (Nikon Eclipse Ti) equipped with a fast camera.

\subsection{Cell culture}

Human cancer cell line MCF-7, were purchased from the American Type Culture Collection and cultured in DMEM medium (4500 $\mathrm{mg} \mathrm{l}^{-1}$ glucose) supplemented with $10 \% \mathrm{FBS}, 100 \mathrm{U} \mathrm{ml}^{-1}$ penicillin and $100 \mu \mathrm{g} \mathrm{ml}^{-1}$ streptomycin at $37^{\circ} \mathrm{C}$ in an atmosphere of $5 \% \mathrm{CO}_{2}$.

\subsection{MTT assay}

An MTT assay was used to determine the cell viability in different conditions. To this aim, cells were plated at $53 \times 10^{3}$ cells ml ${ }^{-1}$ per well in a 24 -well plate. After $3 \mathrm{~d}$ of growth, the culture medium was aspirated; then, $100 \mathrm{ml}$ of DMEM-phenol free medium containing $10 \mathrm{ml}$ of MTT stock solution and $5 \mathrm{mg} \mathrm{ml}^{-1}$ of PBS solution was added to each well. After $1 \mathrm{~h}$ of incubation, the MTT solution was removed and $100 \mathrm{ml}$ of DMSO was added to dissolve MTT-formazan crystals. The absorbance of the converted dye was measured at a wavelength of $570 \mathrm{~nm}$ using an iMark microplate reader (Bio-Rad, Hercules, CA, USA). The relative cell viability was expressed as a percentage of the control MW (MCF-7 cells grown in a commercial MW).

\subsection{Live/dead assay}

Viability of spheroids was qualitatively analyzed using a Live/Dead assay kit (Thermo Fisher Scientific, Inc.). The activity of intracellular esterase induces nonfluorescent, cell-permeant calcein acetoxymethyl to become fluorescent, giving the viable spheroids a green fluorescence. Ethidium homodimer enters and binds to nucleic acids only into damaged cell producing a red fluorescence thus indicating dead cells.

\subsection{Contact angle measurements}

Static Water Contact Angles (WCA) were measured using the sessile drop method and a CAM 200 (KSV Instruments Ltd, Finland) instrument. The measurements reported in table 1 correspond to an average of measurements performed onto many areas of the samples. The errors as standard deviations from the medium value are calculated.

For the MW WCAs, a piece with a surface of about $1 \mathrm{~cm}^{2}$ was broken from the MW culture plate. For MW-PDMS, LOC-PDMS, MW-F10, LOC-F10, and LOCpl measurements, PDMS slides were opportunely prepared, treated with oxygen plasma and functionalized with HFBII and F10 solutions [37]. Finally, in the case of LOBpl, LOB-PDMS and LOB-F10, TMs with a thickness of $2 \mu \mathrm{m}$ have been prepared as reported above for the chips [9]. The F10 coatings on the flat slides and membranes have been deposited using the same procedure reported in the 'chip functionalization' paragraph.

\section{Results and discussion}

Three different chips (MW, LOC and LOB) with millichambers of different internal volume and wettability have been assembled. The simplest chip is represented by a commercial MW, (see figure 1(a)) in which a PDMS (MW-PDMS) or a PDMS/F10 (MWF10) layer was deposited.

Starting from a mold fabricated as reported in [9], LOCs of different wettabilities have been produced by functionalizing the surface via oxygen plasma treatment (soon after plasma, LOCpl, and $3 \mathrm{~d}$ afterwards, LOC-PDMS) and by chemical grafting of F10 (LOCF10) (figure 1(b)). Finally, LOBs with different wettability, following the same procedure of LOCs (named LOBpl, LOB-PDMS and LOB-F10, figure 1(c)), have been prepared.

In table 1 the WCA values of all the chips are reported. As general consideration, all LOBs appear more hydrophilic than LOCs because of the different wettability of the growth chamber basement. It is well known that PDMS layers of various thicknesses react to oxygen plasma treatments by exhibiting different hydrophobic recovery behaviors [10, 24]. Thin PDMS membranes (which represent the growth chamber basements in LOBs) preserve hydrophilicity longer than thick PDMS films (chamber basement of LOCs); 
Table 1. Water contact angle (WCA) values of the produced chips.

\begin{tabular}{|c|c|c|c|c|c|c|c|c|c|}
\hline & \multicolumn{3}{|c|}{ MW } & \multicolumn{3}{|c|}{ LOC } & \multicolumn{3}{|c|}{ LOB } \\
\hline & MW & MW-PDMS & MW-F10 & LOCpl & LOC-PDMS & LOC-F10 & LOBpl & LOB-PDMS & LOB-F10 \\
\hline $\mathrm{WCA}\left({ }^{\circ}\right)$ & $83.8 \pm 0.8$ & $67.0 \pm 0.7$ & $102.0 \pm 3.0$ & $7.4 \pm 0.9$ & $67.0 \pm 0.7$ & $102.0 \pm 3.0$ & $13.2 \pm 5.2$ & $39.1 \pm 6.3$ & $48.8 \pm 0.6$ \\
\hline
\end{tabular}



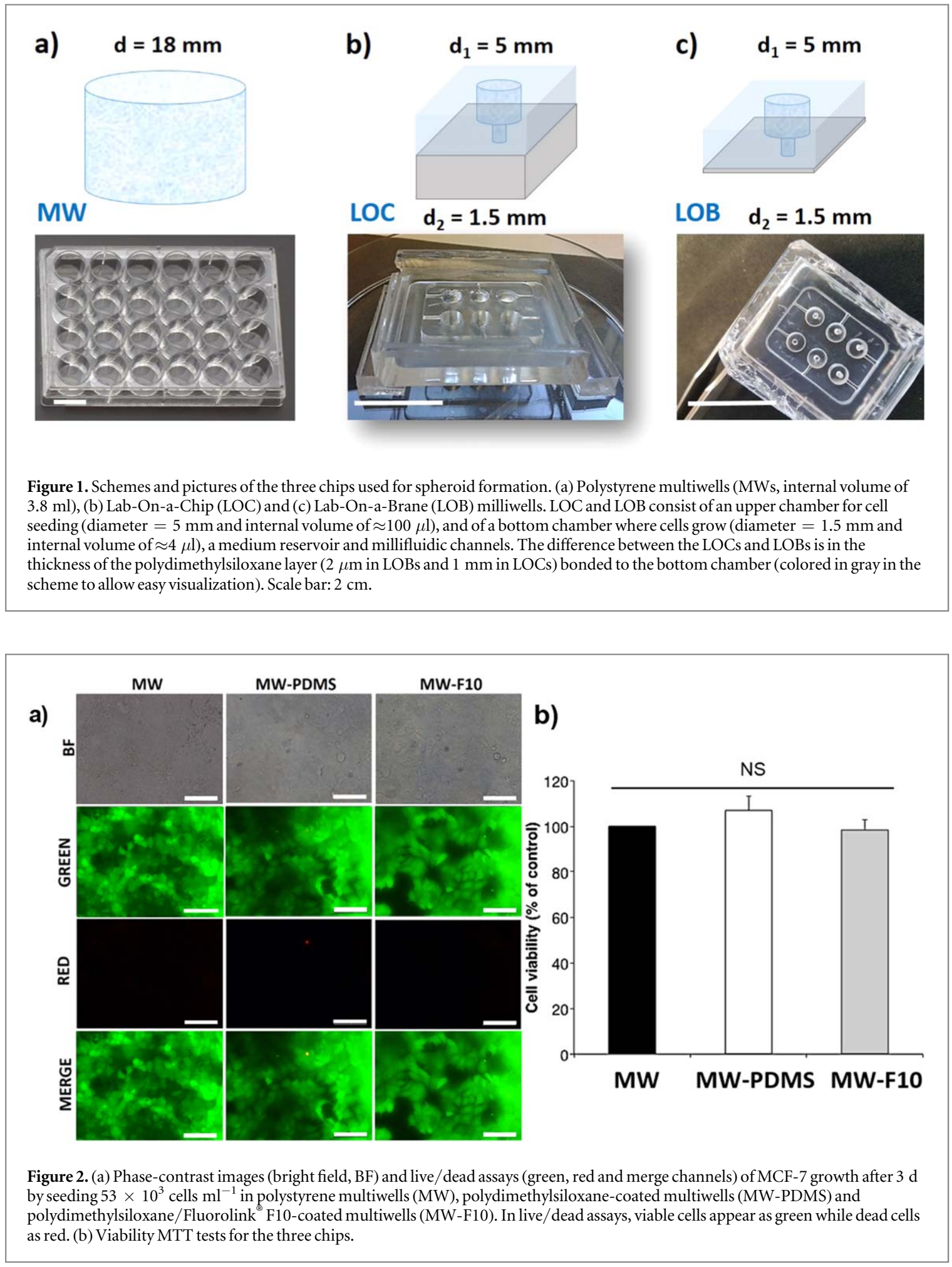

this influences the reactivity towards chemicals and affects F10 functionalization in LOC-F10 and LOBF10. MW-PDMS and MW-F10 behave like LOCs since the surfaces of their growth chambers consist of mm thick PDMS layers.

We performed preliminary experiments to compare cell growth and cell viability in all MW chips (MW, MW-PDMS and MW-F10), by seeding $53 \times 10^{3}$ cells in a volume of $1 \mathrm{ml}$ DMEM and allowing their growth for $3 \mathrm{~d}$. In figure 2, phase contrast images are reported showing that morphology of the observed cell layer was comparable in all the MW chips. As expected, no 3D but only 2D growth occurred and, in addition, no toxic effect was observed in none of them as assessed by the MTT assay results shown in figure 2(b). Moreover, live/dead assays for cells grown on all MW chips were performed in order to further confirm the MTT results and better evaluate the absolute biocompatibility of the F10 coating (figure 2(a)).

Starting from these data and with the aim to provide a more manageable system that requires rather 


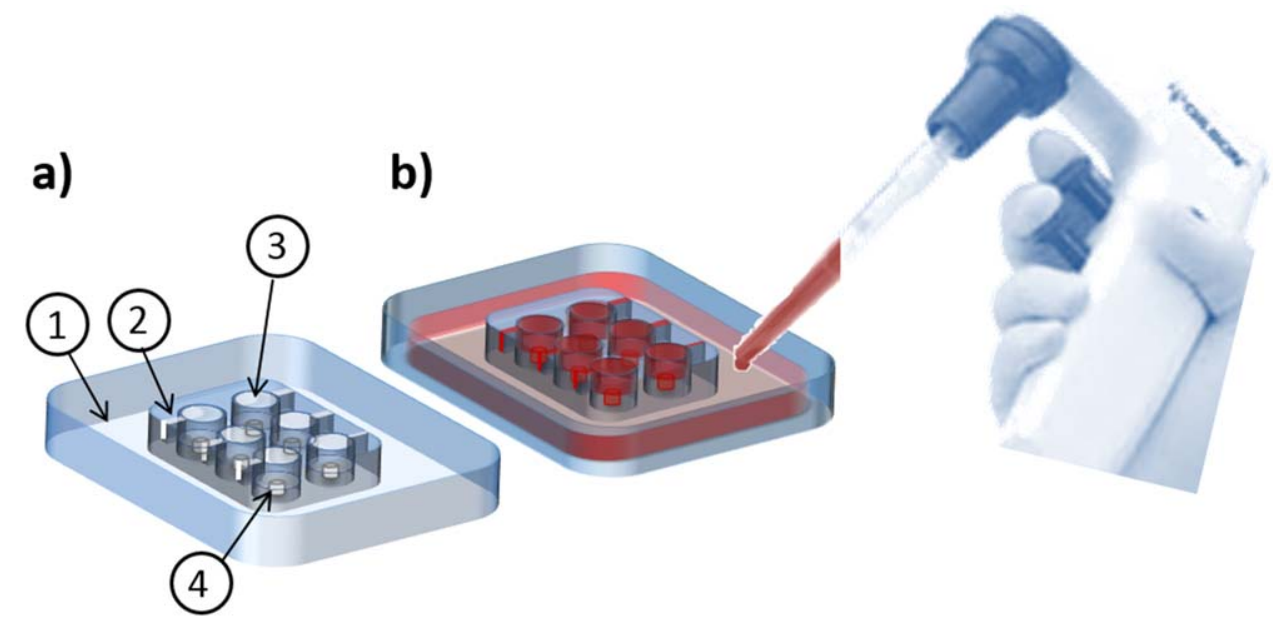

Figure 3. Layout of the millifluidic platform. (a) Overview showing (1) culture medium reservoir, (2) loading fluidic channels, (3) upper chamber for cell seeding and (4) lower chamber for cell growth. (b) Loading of cells suspension solution and medium in milliwells and reservoir respectively.

simple and low cost fabrication processes, LOCs with smaller wells and tunable wettabilities have been designed. The fluidic platform is presented in figure 3 . The LOC design consists of an array of millifluidic channels connected to six milliwells and a lateral reservoir located around the millifluidic network to allow an easy culture medium exchange. Each milliwell consists of an upper chamber for cell seeding with a diameter of $5 \mathrm{~mm}$ and of a smaller (diameter $=1.5 \mathrm{~mm}$ ) lower chamber for cell growth with no semi-permeable separation barrier between them. The seeding chamber was designed to guarantee an easy and homogeneous filling of the growth chamber which is very small and, in some chips, strongly hydrophobic. In the seeding chamber cells do not grow in the form of spheroids, but have the tendency to create amorphous 2D clusters (not reported). The lateral reservoir can host up to $2 \mathrm{ml}$ of medium, a volume large enough to supply continuous nutrients for the cells in the wells for several days' experiments. The fluidic channels allow medium flow from the reservoir to each well under a capillary action. During the cell seeding operation, a volume of $100 \mu \mathrm{l}$ of cell suspension has been introduced into each milliwell, then the culture medium was loaded in the reservoir. As final step, the LOCs/LOBs were placed in a Petri dish in order to reduce the medium evaporation during incubation.

Three LOCs with hydrophilic, hydrophobic and oleophobic features have been filled with cells at the concentration of $50 \times 10^{3}$ cells ml $^{-1}$ and their morphology observed after $3 \mathrm{~d}$ of growth. Spheroids were observed in the case of hydrophobic and oleophobic wells (figures 4(a) and (b)). Occasionally, areas of 2D growth were also visible (see insets of figures 4(a) and (b)). On the other hand, no spheroids were observed by seeding LOC-PDMS and LOC-F10 with cells at a lower density (seeding of $5 \times 10^{3}$ cells $\mathrm{ml}^{-1}$ ) (images not shown). It is interesting to note that, although the shape and the wettability of the LOC wells were similar to the MW ones, 3D aggregation seemed to be favored only in LOCs.

As expected, considering the wettability of the wells, in hydrophilic LOCs no spheroids but only 2D growth was observed (see figures 5(a) and (c)).

Finally, starting from the same mold, LOBs with basal membranes of different wettabilities have been produced. Beyond being more hydrophobic (as shown in table 1), LOBs should appear stiffer than LOCs by roughly one order of magnitude, considering the values reported in literature for TMs and bulk PDMS [31]. As figures 4(c), (d), 5(b) and (d) show, cells seem to aggregate and form spheroids in LOBs independently of the wettability of the substrate. In hydrophobic and oleophobic wells a cell density of $50 \times 10^{3}$ cells ml $^{-1}$ was necessary; at lower cell density (see insets of figures 4 (c) and (d)) no spheroids were visible in LOB-PDMS as well as in LOB-F10. A lower surface density $\left(5 \times 10^{3}\right.$ and $5 \times 10^{2}$ cells ml ${ }^{-1}$ ) was enough to observe $3 \mathrm{D}$ growth even if cells were in contact with hydrophilic wells. The different threshold to form spheroids in LOBs can be explained considering that the cell seeding density is calculated without taking into consideration the real amount of cells that penetrate into the wells. Since water solutions can more easily fill into hydrophilic wells, a large amount of cells can be present in LOCpl even starting from a more diluted cell suspension. Moreover, less tendency towards 2D aggregation was also observed in other areas of LOBs if compared with LOCs.

As further experiments, time course studies have been performed to monitor the process of spheroid formation and to assess their viability. Figure 6 reports the main results of this study for LOB-F10 and LOCF10, although similar images have been acquired for LOBpl, LOB-PDMS and LOC-PDMS as well (data not 


\section{a) LOC-PDMS}

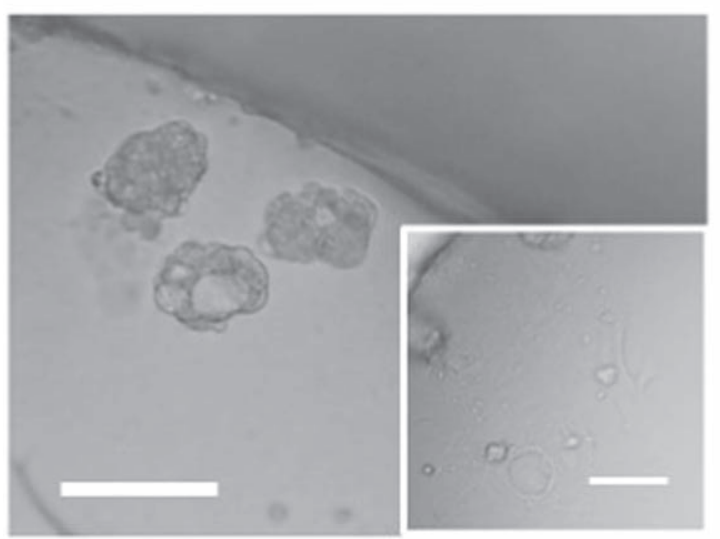

c)

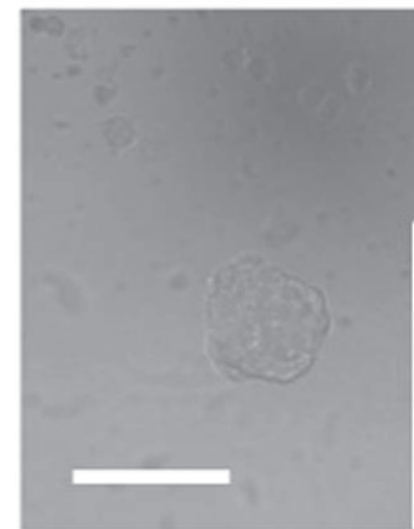

LOB-PDMS

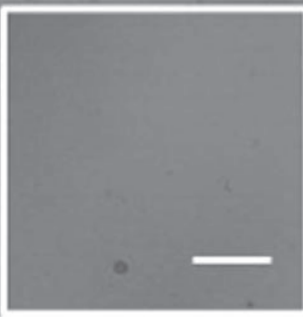

b) LOC-F10

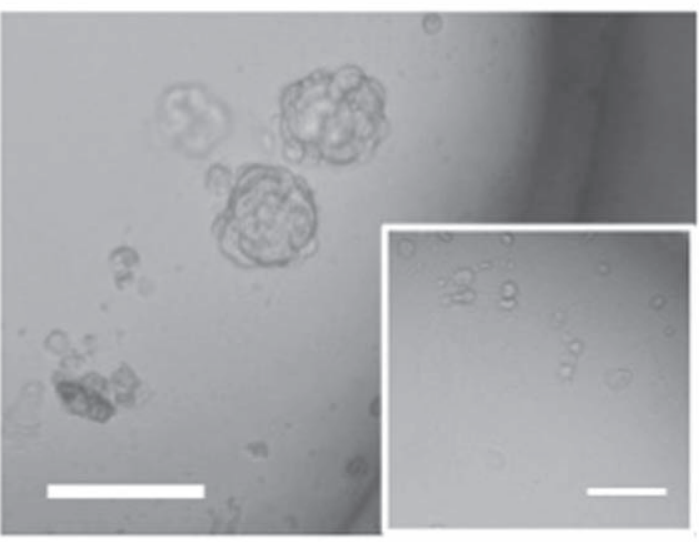

d)

LOB-F10

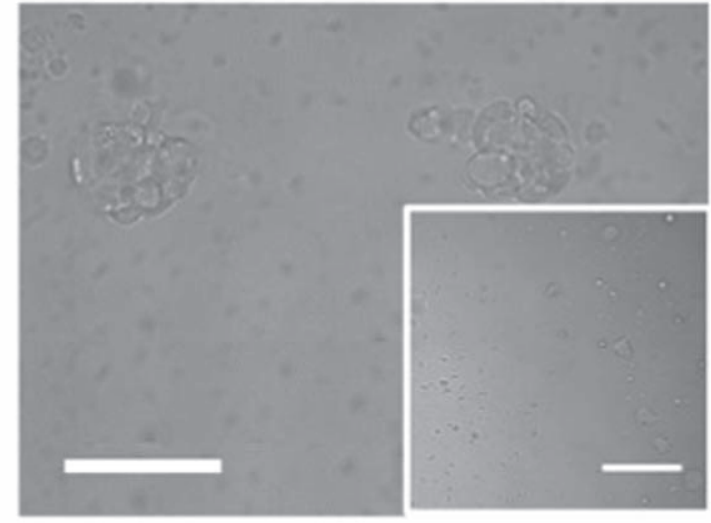

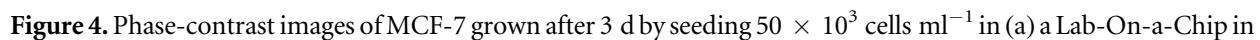
polydimethylsiloxane (LOC-PDMS) and (b) a Lab-On-a-Chip in polydimethylsiloxane coated by a Fluorolink ${ }^{\oplus 10}$ layer (LOC-F10). In the insets: areas of the LOCs showing 2D aggregation. Phase-contrast images of MCF-7 grown after $3 \mathrm{~d}$ by seeding $50 \times 10^{3}$ cells ml ${ }^{-1}$ in (c) a Lab-On-a-Brane in polydimethylsiloxane (LOB-PDMS) and (d) a Lab-On-a-Brane in polydimethylsiloxane coated by a Fluorolink ${ }^{\oplus}$ F10 layer (LOB-F10). In the insets: MCF-7 growth after $3 \mathrm{~d}$ by seeding $5 \times 10^{3}$ cells $\mathrm{ml}^{-1}$. Scale bar: $100 \mu \mathrm{m}$.

shown). The growth process was monitored at 2, 3, 4 and $5 \mathrm{~d}$ and it was found that very small spheroids are present already after $2 \mathrm{~d}$ of growth becoming larger at day 3 until reaching a dimension of about 70-100 $\mu \mathrm{m}$ after $4 \mathrm{~d}$ of growth. This dimension appeared to be kept also at day 5 (figures 6(a) and (b)). According to the observed trend, we guess that the spheroids could originate by a combination of cell aggregation and cell growth as sketched in figure 6(c). Furthermore, at the 4th day of growth, spheroids obtained in LOB-F10 and LOC-F10 (figure 6), as well as in all other chips (not shown), were subjected to a live/dead fluorescence assay that confirmed their viability, thus excluding the presence of a necrotic core mass (figures 6(a) and (b)).

Regarding the different results observed in LOCs/ LOBs and MWs chips, we believe that the 2D aggregation in MWs (figure 2) is favored by the low tendency of cells to interact each other in a large volume. The drastic reduction of well volume resulted in $3 \mathrm{D}$ cell aggregation for low adhesion LOC-PDMS and LOC-
F10. In highly hydrophilic wells (LOCpl), the cell-substrate interactions seem to overcome the cell-cell interactions, thus resulting into a $2 \mathrm{D}$ growth. It was reported that cell adhesion on strongly hydrophilic (WCA $<40^{\circ}$ ) or hydrophobic surfaces (WCA $>90^{\circ}$ ) is mediated by serum proteins (e.g. albumin) and influenced by the surface functional groups, their surface density, and the kinds of cells [28, 29]. Albumin strongly adsorbs and resists replacement by cell adhesive proteins on hydrophobic SAMs. On the other hand, cells adhere to albumin-pre-adsorbed hydrophilic SAMs on which albumin displacement with cell adhesive proteins occurs. This was probably the mechanism, which explains the presence of spheroids and 2D growth in LOC-PDMS chips (figure 4(a) and inset) and only $2 \mathrm{D}$ growth in LOCpl chips (figures 5(a) and (c)).

Although with the same final results (see figures 4(b)), 3D aggregation in LOC-F10 is probably not mediated by albumin since it does not adsorb on 
a)

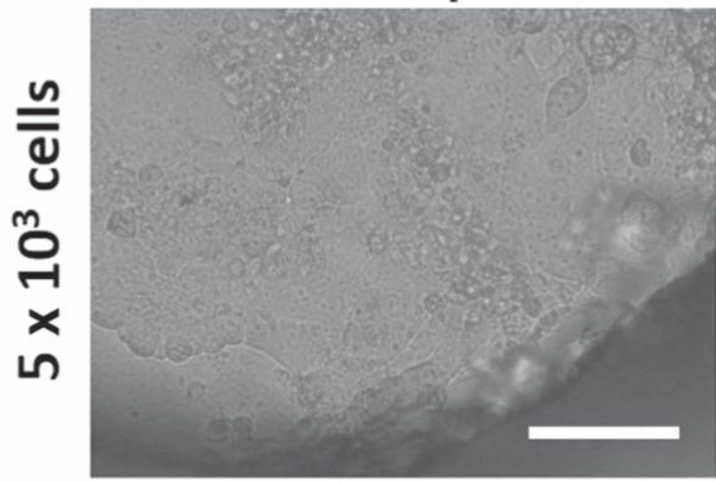

c)

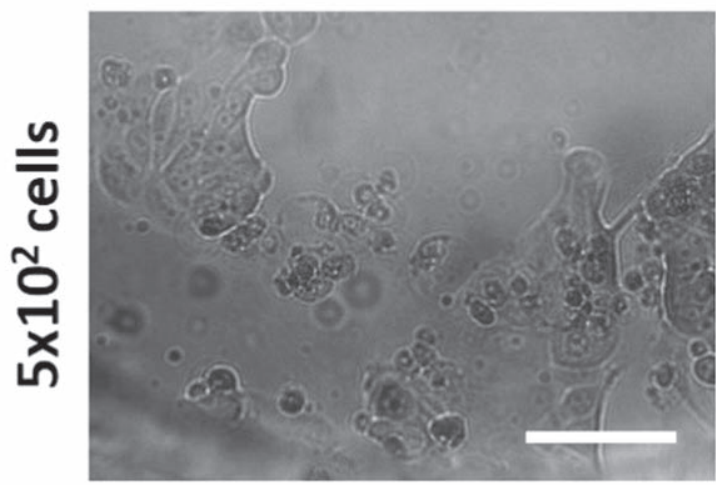

b)

LOBpl

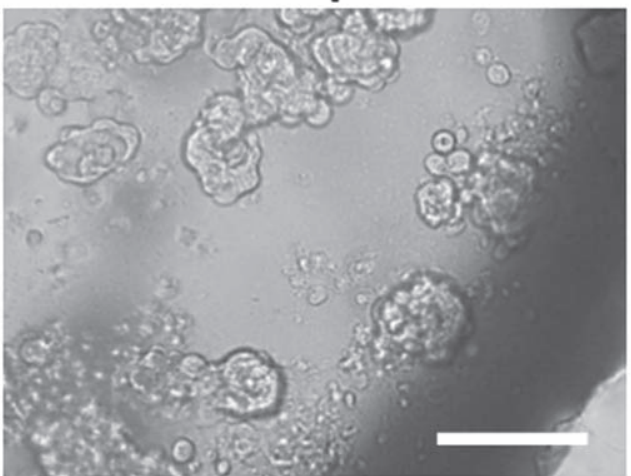

d)

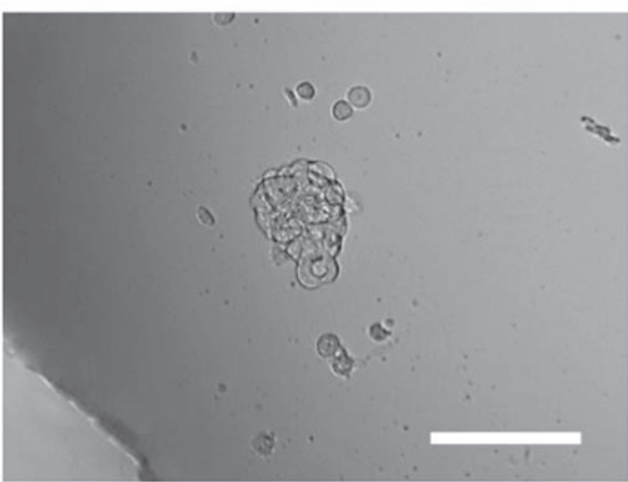

Figure 5. Phase-contrast images of MCF-7 grown after $3 \mathrm{~d}$ in a Lab-On-a-Chip in polydimethylsiloxane treated with oxygen plasma (LOCpl) by seeding (a) $5 \times 10^{3}$ cells ml $^{-1}$ and (c) $5 \times 10^{2}$ cells ml $^{-1}$. Phase-contrast images of MCF-7 growth after $3 \mathrm{~d}$ in a Lab-Ona-Brane in polydimethylsiloxane treated with oxygen plasma (LOBpl) by seeding (b) $5 \times 10^{3} \mathrm{cells} \mathrm{ml}^{-1}$ and (d) $5 \times 10^{2}$ cells ml ${ }^{-1}$. Scale bar: $100 \mu \mathrm{m}$

fluorinated surfaces [34-36]. Therefore, F10 oleophobic surface probably inhibits both albumin and cell protein adhesion.

Considering the low WCAs calculated for LOBs (see table 1) and the strong influence of the wettability parameter on cell aggregation, the formation of $3 \mathrm{D}$ assemblies in all LOBs was unexpected.

In a recent work [26], it was reported that insulinproducing beta cells display excellent viability and tend to interact with each other forming spheroids if cultured on hemispherical and sub-hemispherical microwells coated with Pluronic 123, an anti-adhesive film for cells. The same cells, grown on a Pluronic 123 coated flat surface, poorly adhere to each other and thus do not form spheroids, inducing apoptosis in the cell population.

Considering these results, it would be possible that on flat strongly hydrophilic PDMS surfaces (WCA $<40^{\circ}$ ), the albumin coating, which first forms at the solid-liquid interface, is soon replaced by the protein cell adhesions, and therefore $2 \mathrm{D}$ aggregates are observed. In a hemispherical well, given the presence of albumin on the surface and the need to adapt cell morphology to bind on a curved surface, it is likely that cell-substrate interactions may result weak and cell-cell interactions are favored with high probability to form spheroids. In the case of LOBs, even if the surface is not hemispherical, given the possible deformation of the TMs by the fluid weight [31], a subhemispherical milliwell can be produced and this may obstacle cell protein anchoring and force cells to aggregate in the form of spheroids.

Another aspect to consider is the higher permeability of LOBs to oxygen and/or to carbon dioxide. It was demonstrated that, under the same conditions, spheroids of mouse insulinoma cell line grow on PDMS sheets and not on polystyrene honeycomb microwell sheets as result of the higher oxygen supply, which favors the aerobic cellular metabolism and indirectly supports a 3D cellular reorganization [27]. Furthermore, oxygen permeability could be enhanced by reducing the thickness of the PDMS membrane as recently reported by Lee et al [43]. In this work, the authors measured an oxygen penetration time of about $12 \mathrm{~s}$ through the $8 \mu \mathrm{m}$ thick PDMS concave microwells, and of about $200 \mathrm{~s}$ through the $1.05 \mathrm{~mm}$ ones. As final result, an increased viability and reduced hypoxic regions of pancreatic islet spheroids in membrane concave microwells have been observed [43]. Hence, considering the fast oxygen supply to MCF-7 in LOBs (due to the $2 \mu \mathrm{m}$ thick PDMS basement of the growth chamber), we could speculate that a different cellular reorganization is promoted 

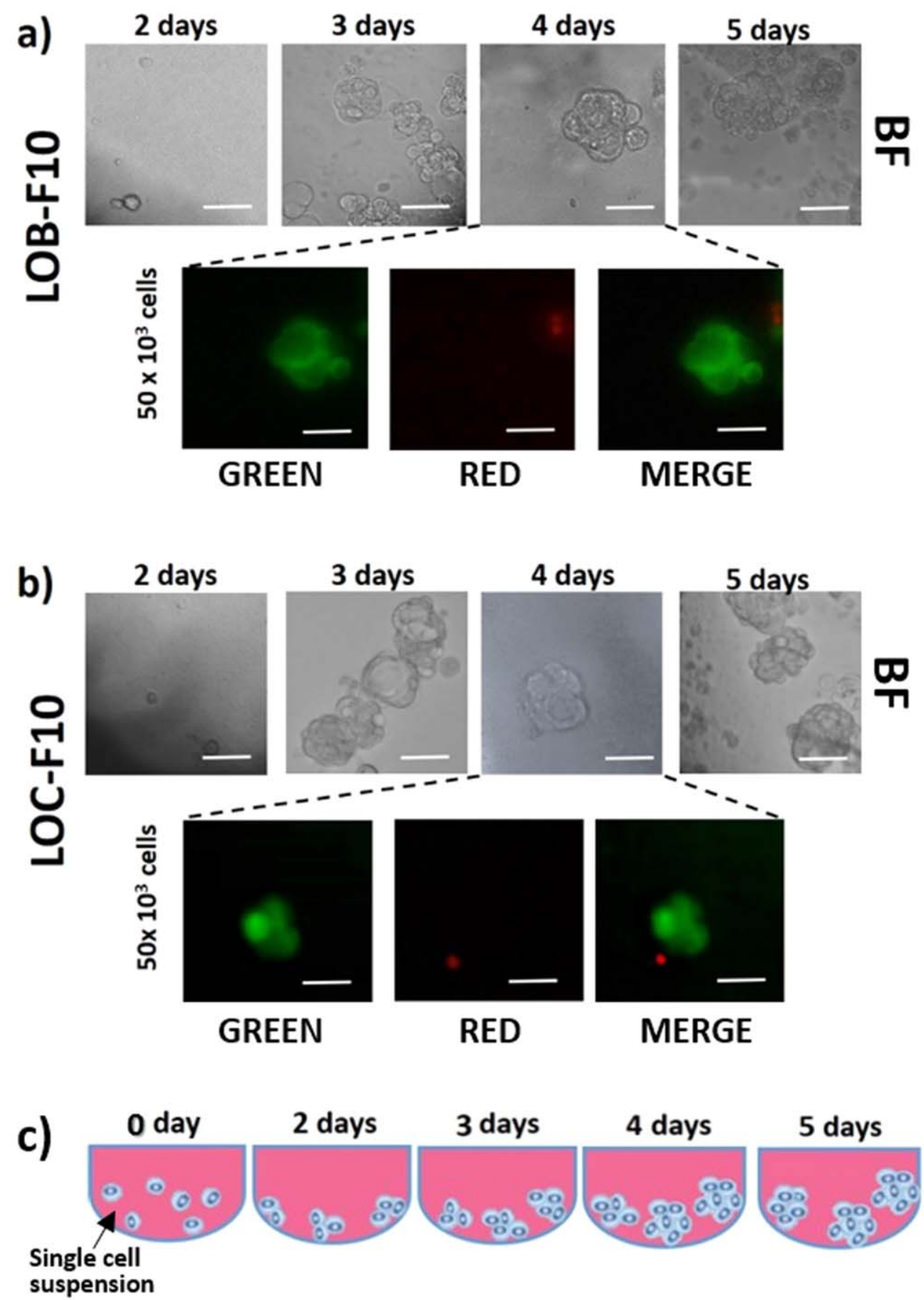

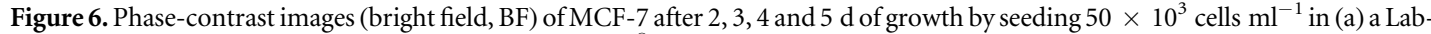
On-a-Brane in polydimethylsiloxane coated by Fluorolink ${ }^{\oplus} \mathrm{F} 10$ (LOB-F10) and in (b) a Lab-On-a-Chip in polydimethylsiloxane coated by Fluorolink ${ }^{\circledast}$ F10 (LOC-F10). Live/dead assays at day 4 correspond to green, red and merge channels. Viable cells appear as green while dead cells as red. Scale bar: $50 \mu \mathrm{m}$. (c) Scheme of the process of the spheroid formation in LOBs. Growth process monitored at 0 (single cell suspension), 2, 3, 4 and $5 \mathrm{~d}$ with small spheroids after $2 \mathrm{~d}$ of growth, larger at 3 day and with a dimension of about $100 \mu \mathrm{m}$ after 4 and $5 \mathrm{~d}$ of growth.

which may drive cells towards 3D aggregation rather than 2D aggregation.

\section{Conclusions}

In this work we demonstrate the potentiality of the LOB approach in promoting 3D cell growth independent of the substrates wettability. This result was attributed to the TMs flexibility and high oxygen/ carbon dioxide permeability. Further studies are needed to better elucidate the mechanism which drives the $3 \mathrm{D}$ aggregation as well as the advantages to use oleophobic coatings to reduce the absorption/adsorption of small molecules of the cell culture medium. As improvement of the LOB approach, the modulation of the dimensions of the growth chamber and the optimization of cells/surface ratios could be the 
subject of future study to overcome the difficulties in controlling the uniformity of the spheroids and to allow the production of a single spheroid of controlled size per chamber. However, on the basis of these results, we believe that LOBs could be useful not only as multi-well chips to reduce operation time for cell seeding and medium refresh, but also to provide a tool for applying mechanical stimuli, monitor cell stiffness and study the metabolism of molecules permeable to PDMS membrane in response to drug treatment with interesting outcome in cellular biology.

\section{Acknowledgments}

We thank F Montagna for technical assistance in the preparation of the mold via stereolithography and the project 'Cluster in Bioimaging' (code QZYCUM0), 'Aiuti a sostegno dei cluster tecnologici regionali 2014', Bando Regione Puglia n. 399 del 28/07/2014).

\section{ORCID iDs}

L Moroni (1) https://orcid.org/0000-0003-1298-6025 R Rella (10 https://orcid.org/0000-0002-9696-1476 V Arima (ib https://orcid.org/0000-0002-3429-8365

\section{References}

[1] Chen XY, Shen J N, Hu Z L and Huo XY 2016 Manufacturing methods and applications of membranes in microfluidics Biomed. Microdevices 1813

[2] Chen X Y and Shen J N 2017 Review of membranes in microfluidics J. Chem. Technol. Biotechnol. 92 271-82

[3] de Jong J, Lammertink R G H and Wessling M 2006 Membranes and microfluidics: a review Lab Chip 6 1125-39

[4] Karim I B, Vinoy T and Palaniappan S 2016 Lab-on-a-brane: nanofibrous polymer membranes to recreate organ-capillary interfaces J. Micromech. Microeng. 26035013

[5] Eddings M A and Gale B K 2006 A PDMS-based gas permeation pump for on-chip fluid handling in microfluidic devices J. Micromech. Microeng. 16 2396-402

[6] Huang S B et al 2014 A clogging-free microfluidic platform with an incorporated pneumatically driven membrane-based active valve enabling specific membrane capacitance and cytoplasm conductivity characterization of single cells Sensors Actuators B $190928-36$

[7] Wu CY, Liao W H and Tung Y C 2011 Integrated ionic liquidbased electrofluidic circuits for pressure sensing within polydimethylsiloxane microfluidic systems Lab Chip 11 1740-6

[8] Chaudhury A R, Pantazis A K and Chronis N 2016 An image contrast-based pressure sensor Sensors Actuator A 245 63-7

[9] Zizzari A et al 2017 Self-powered catalytic microfluidic platforms for fluid delivery Colloids Surf. A 532 257-62

[10] Zizzari A et al 2018 Highly sensitive membrane-based pressure sensors (MePS) for real-time monitoring of catalytic reactions Anal. Chem. 90 7659-65

[11] Cha Met al 2008 Biomolecular detection with a thin membrane transducer Lab Chip 8 932-7

[12] Sang S B et al 2015 PDMS micro-membrane capacitance-type surface stress biosensors for biomedical analyses Microelectron. Eng. 13433-7

[13] Thuenauer R, Rodriguez-Boulan E and Romer W 2014 Microfluidic approaches for epithelial cell layer culture and characterisation Analyst 1393206-18
[14] Wang L et al 2008 An automatic and quantitative on-chip cell migration assay using self-assembled monolayers combined with real-time cellular impedance sensing $\mathrm{Lab}$ Chip 8 872-8

[15] Jie M S et al 2016 Integrated microfluidic system for cell coculture and simulation of drug metabolism RSCAdv. 6 54564-72

[16] Saadin Ket al 2013 Enrichment of tumor-initiating breast cancer cells within a mammosphere-culture microdevice Biomed. Microdevices 15 645-55

[17] Zhang C T et al 2016 A microfluidic transwell to study chemotaxis Exp. Cell Res. 342 159-65

[18] Lopa S et al 2015 Fabrication of multi-well chips for spheroid cultures and implantable constructs through rapid prototyping techniques Biotechnol. Bioeng. 112 1457-71

[19] Skardal A, Shupe T and Atala A 2016 Organoid-on-a-chip and body-on-a-chip systems for drug screening and disease modeling Drug Discovery Today 21 1399-411

[20] van Duinen V et al 2015 Microfluidic 3D cell culture: from tools to tissue models Curr. Opin. Biotechnol. 35 118-26

[21] Zheng F et al 2016 Organ-on-a-chip systems: microengineering to biomimic living systems Small 12 2253-82

[22] Zhang B, Korolj A, Lai B F L and Radisic M 2018 Advances in organ-on-a-chip engineering Nat. Rev. Mater. $3257-78$

[23] van der Helm M W et al 2016 Microfluidic organ-on-chip technology for blood-brain barrier research Tissue Barriers 4 e1142493

[24] Liu T Q, Chien C C, Parkinson L and Thierry B 2014 Advanced micromachining of concave microwells for long term on-chip culture of multicellular tumor spheroids ACS Appl. Mater. Interfaces 6 8090-7

[25] Tu T Y et al 2014 Rapid prototyping of concave microwells for the formation of 3D multicellular cancer aggregates for drug screening Adv. Healthc. Mater. 3 609-16

[26] Forget A et al 2017 Rapid fabrication of functionalised poly (dimethylsiloxane) microwells for cell aggregate formation Biomater. Sci. 5 828-36

[27] Shinohara $\mathrm{M}$ et al 2014 Combination of microwell structures and direct oxygenation enables efficient and size-regulated aggregate formation of an insulin-secreting pancreatic betacell line Biotechnol. Prog. 30 178-87

[28] Sun D P et al 2014 A novel three-dimensional microfluidic platform for on chip multicellular tumor spheroid formation and culture Microfluid. Nanofluid. 17 831-42

[29] Yeon S E et al 2013 Application of concave microwells to pancreatic tumor spheroids enabling anticancer drug evaluation in a clinically relevant drug resistance model PLoS One 8 e 73345

[30] Albritton J Let al 2016 Ultrahigh-throughput generation and characterization of cellular aggregates in laser-ablated microwells of poly(dimethylsiloxane) RSC Adv. 6 8980-91

[31] Kang E et al 2013 Large-scale, ultrapliable, and free-standing nanomembranes Adv. Mater. 25 2167-73

[32] Arima Y and Iwata H 2007 Effect of wettability and surface functional groups on protein adsorption and cell adhesion using well-defined mixed self-assembled monolayers Biomaterials 28 3074-82

[33] Toepke M W and Beebe D J 2006 PDMS absorption of small molecules and consequences in microfluidic applications $L a b$ Chip 6 1484-6

[34] Xie H J, Zhao Z B, An S S and Jiang Y 2015 The influence of the surface properties of silicon-fluorine hydrogel on protein adsorption Colloids Surf. B $1361113-9$

[35] Tokuda K, Ogino T, Kotera M and Nishino T 2015 Simple method for lowering poly(methyl methacrylate) surface energy with fluorination Polym. J. 47 66-70

[36] Bianco M et al 2015 Non-biofouling fluorinated block copolymer coatings for contact lenses Sci. Adv. Mater. 7 1387-94

[37] Bianco M et al 2018 Integrated microfluidic viscometer for edible oil analysis Sensors Actuators B 265 91-7 
[38] Milani Ret al 2013 Hydrophobin: fluorosurfactant-like properties without fluorine Soft Matter 9 6505-14

[39] Gazzera L et al 2015 Hydrophobin as a nanolayer primer that enables the fluorinated coating of poorly reactive polymer surfaces Adv. Mater. Interfaces 21500170

[40] Bailey M Jet al 2002 Process technological effects of deletion and amplification of hydrophobins I and II in transformants of Trichoderma reesei Appl. Microbiol. Biotechnol. 58 $721-7$
[41] Paananen A et al 2003 Structural hierarchy in molecular films of two class II hydrophobins Biochemistry 42 5253-8

[42] Linder Met al 2001 The hydrophobins HFBI and HFBII from trichoderma reesei showing efficient interactions with nonionic surfactants in aqueous two-phase systems Biomacromolecules 2511-7

[43] Lee G et al 2018 Enhanced oxygen permeability in membranebottomed concave microwells for the formation of pancreatic islet spheroids Acta Biomater. 65 185-96 